\title{
Agricultura familiar e desenvolvimento local: os desafios para a sustentabilidade econômico-ecológica na comunidade de Palmares II, Parauapebas, PA
}

Family agriculture and local development: challenges to sustainable economic and ecological community of Palmares II Parauapebas city, Pará state in Brazil

L'agriculture familiale et le développement local: défis pour la durabilité économique et écologique de la localité de Palmares II ville de Parauapebas, état du Pará au Brésil Agricultura familiar y desarrollo local: los desafios para una sustentabilidad económicoecológica en la comunidad de Palmares II,Parauapebas, PA (Brasil)

\author{
Alessio Moreira dos Santos* \\ Danielle Mitja**
}

Recebido em 18/6/2011 revisado e aprovado em 20/10/2011; aceito em 18/12/2011

\begin{abstract}
Resumo: Este artigo tem por objetivo analisar as atividades agrícolas dos agricultores familiares e suas repercussões sobre o meio ambiente no Assentamento Palmares II, localizado no município de Parauapebas, PA, e discutir as potencialidades para o desenvolvimento local. A sustentabilidade econômico-ecológica dos estabelecimentos familiares poderá ser alcançada através da capacitação das famílias assentadas em técnicas agrícolas de conservação dos recursos naturais e capacitação para a agroindustrialização de produtos a serem comercializados no mercado local. Palavras-chave: Agricultura familiar. Desenvolvimento Local. Sustentabilidade.
\end{abstract}

Abstract: This article aims to analyze the agricultural activities of family farmers and its impact on the environment in Palmares II Settlement, located in the municipality of Parauapebas, PA, and discuss the potential for local development. The economic and ecological sustainability of family farms can be achieved through the empowerment of families settled in farming techniques that conserve natural resources and training for the industrialization of the products being sold in local market.

Key words: Family agriculture. Local Development. Sustainability.

Résumé: Cet article vise à analyser les activités agricoles des paysans et leur impact sur l'environnement dans la localité de Palmares II, située dans la municipalité de Parauapebas, état du Pará, et de discuter du potentiel pour le développement local. La durabilité économique et écologique des exploitations familiales peut être atteinte en favorisant l'autonomie des familles installées, en matière de techniques agricoles qui préservent les ressources naturelles et de formation pour l'industrialisation des produits agricoles vendus sur le marché local.

Mots-clés: Agriculture familiale. Développement local. Durabilité.

Resumen: El objetivo de este artículo es de analizar las actividades agrícolas de los habitantes de Palmares II, en el município de Parauapebas, Estado del Pará, y sus impactos sobre el medio ambiente para discutir de sus possibles contribuciones para el desarrollo local. La sustentabilidad económica y ecológica de la agricultura familiar puede lograrse mediante la difusión de técnicas de cultivo que conservan los recursos naturales y la capacitación de los agricultores para la industrialización de productos que se venden en el mercado local.

Palabras claves: Agricultura familiar. Desarrollo local. Sustentabilidad.

\section{Introdução}

O agronegócio brasileiro tem ganhado destaque no cenário mundial com uma taxa de crescimento médio de $5 \%$ ao ano (MELO, 2004). Segundo dados do Ministério da Agricultura (2004), o agronegócio é responsável por $33 \%$ do Produto Interno Bruto (PIB), $42 \%$ das exportações totais e $37 \%$ dos empregos brasileiros. Para Pinto e Silva (2005), o Consenso de Washington ${ }^{1}$ trouxe mudanças na competitividade do agronegócio brasileiro a partir dos anos 1990, passando a ser o principal setor exportador brasileiro.

Estudos realizados por Guilhoto et al. (2006) concluem que, no período de 1995 a 2003, o agronegócio familiar teve participação significativa na riqueza nacional. Em 2003, contribuiu com 10,1 \% (R $\$ 157$ bilhões) do PIB brasileiro e um terço do PIB do agronegócio nacional. O desempenho da agropecuária familiar e do agronegócio a ela articulada

\footnotetext{
* Engenheiro Agrônomo. Mestre em Gestão dos Recursos Naturais e Desenvolvimento Local na Amazônia, Universidade Federal do Pará (UFPA/Belém, PA). E-mail: alessio@ufpa.br

** Doutora em Biologia Vegetal pela Université Pierre et Marie Curie, França. Pesquisadora do Institut de Recherche Pour Le Développement (IRD/França). E-mail: danielle.mitja@ird.fr

${ }^{1}$ Conjunto de medidas econômicas e políticas formuladas para orientar a economia dos países na América Latina. Sua base principal é política de abertura de mercado (PINTO e SILVA, 2005).
} 
vem superando nos últimos anos as taxas de crescimento relativas ao segmento patronal. No entanto o agronegócio familiar apresenta algumas limitações que impedem que esses resultados sejam ainda melhores. São eles: a insuficiência de terras, as dificuldades creditícias, o menor aporte tecnológico, a fragilidade da assistência técnica e a subutilização da mão-de-obra (GUILHOTO et al., 2006). Sobre essa contradição, Schmitz e Mota (2007) argumentam que, apesar da importância econômica, entre outros, para a produção de alimentos e produtos básicos para o setor de transformação, os valores da renda e dos investimentos na agricultura familiar são baixos.

A agricultura familiar se apresenta como alternativa modeladora de um desenvolvimento menos excludente e ambientalmente mais equilibrado. No debate sobre o desenvolvimento local, as especificidades produtivas e geradoras de renda e ocupação, expressivas na agricultura familiar, têm importância econômica e social e são motivadoras de políticas públicas (OLIVEIRA; RIBEIRO, 2002).

$\mathrm{Na}$ região Amazônica, a agricultura familiar se manifesta de forma mais característica que em outras regiões, constituindo a base onde se aplica a extração dos recursos naturais e a maior parte da produção de alimentos. Há a predominância nessa região de agricultores familiares em áreas de fronteira e em áreas antigas de colonização, produzindo culturas temporárias e permanentes, além da exploração extrativa, ocasionando mudança da base produtiva em suas propriedades com a integração ao mercado (GALVÃO et al., 2005). As atividades dos agricultores familiares nos projetos de assentamento da região são importantes na produção de alimentos. Entretanto as atividades agropecuárias praticadas influenciam negativamente os Serviços Ecossistêmicos (SE) realizados pelo meio ambiente.

Este trabalho pretende analisar as atividades produtivas - e suas potencialidades para o desenvolvimento local - dos agricultores familiares da comunidade de Palmares II, município de Parauapebas, PA, sob a ótica da sustentabilidade econômicoecológica. Ao mesmo tempo, pretende divulgar dados de diversidade vegetal do Projeto de Assentamento Palmares II, obtidos através do Projeto de Pesquisa AMAZ_ES intitulado: "Serviços ecossistêmicos e sustentabilidade das paisagens agrosilvipastoris da Amazônia Oriental" 2 .

\section{Caracterização do território de estudo}

1.1 O Assentamento Palmares II na região sudeste do Pará

O território do sudeste do Pará ${ }^{3}$ foi um dos 40 territórios rurais em todo o Brasil que, a partir de 2003, foi contemplado com a política de desenvolvimento territorial do Ministério do Desenvolvimento Agrário (PTDRS, 2006) ${ }^{4}$. É constituído pelos municípios de Eldorado dos Carajás, Itupiranga, Marabá, Nova Ipixuna, Parauapebas, São Domingos do Araguaia e São João do Araguaia, totalizando uma área que corresponde a 3\% do Estado, contando com dois grandes centros regionais, Marabá e Parauapebas, os quais, juntos, ocupam $60 \%$ da área do território (MDA/SDT, 2007). Em 2008, o Ministério do Desenvolvimento Agrário criou o programa "Territórios da Cidadania", com o objetivo de promover o desenvolvimento de regiões com baixo dinamismo econômico, especialmente no meio rural, assegurando o acesso à cidadania e superação da pobreza. Atualmente há 120 territórios em todo o Brasil, o Território do Sudeste do Pará, agora chamado "Território da Cidadania Sudeste Paraense" passou a contar com mais sete municípios (14 no total),

\footnotetext{
${ }^{2}$ AMAZ_ES é um projeto interdisciplinar de pesquisa cujo objetivo é estabelecer relações entre as práticas de gestão de agricultores familiares e seus serviços ecossistêmicos em 06 diferentes localidades na Amazônia Brasileira e Colombiana. É um projeto interinstitucional, com envolvimento de cerca de 70 pesquisadores de diversas instituições do Brasil, França e Colômbia. A coordenação geral é exercida por Patrick Lavelle, do IRD. Os dados de diversidade vegetal são do grupo de biodiversidade, coordenado por Izildinha Miranda da UFRA.

${ }^{3}$ No âmbito do Programa de Desenvolvimento Sustentável dos Territórios Rurais, o "território" é conceituado como um espaço físico, geograficamente definido, geralmente contínuo, compreendendo cidades e campos. Os territórios rurais são os territórios descritos anteriormente onde predominam elementos rurais, incluindo pequenas e médias cidades e vilas ou povoados com certo nível de urbanização (MDA/SDT, 2007).

${ }^{4}$ O Plano Territorial de Desenvolvimento Rural Sustentável (PTDRS), foi coordenado pelo Laboratório Sócio-Agronômico do Tocantins (LASAT) da UFPA, a partir de um programa desenvolvido pela Secretaria de Desenvolvimento Territorial (SDT) do Ministério do Desenvolvimento Agrário (MDA).
} 
ampliando sua área de atuação para atender 14.647 agricultores familiares e 26.146 famílias assentadas (MDA, 2008).

No Território do sudeste do Pará, encontram-se mais de 160 Projetos de Assentamentos (PA's) que beneficiam mais de 18.500 famílias. A ocupação da região ocorreu através de grandes empreendimentos apoiados pelo governo militar e baseados na pecuária de corte extensiva, que acarretou áreas convertidas em pastagens e culminou com o desaparecimento de grandes áreas de florestas a partir dos anos 70. Em geral, atualmente a paisagem do território possui grandes áreas de pastagens, e a pecuária é a atividade agrícola mais importante. O nível de desmatamento é alto, e alguns municípios apresentam situação crítica (São Domingos do Araguaia - 13\% de floresta e Eldorado dos Carajás - $15 \%$ de floresta), outros municípios possuem maiores taxas de cobertura florestal explicadas pela presença de FLONAS, APAS e Reservas indígenas (Parauapebas - 80,82 $\%$, Marabá - 52,99 \% e Itupiranga - 51,16 \%) (PTDRS, 2006).

O Projeto de Assentamento Palmares II, que está localizado a $20 \mathrm{~km}$ da cidade de Parauapebas, Pará e, aproximadamente, a 700 $\mathrm{km}$ de Belém, foi ocupado pelos agricultores familiares em 1994, oficializado pelo INCRA em 1995, possui uma área de 14.922 hectares e 517 famílias assentadas (MICHELOTTI, 2008). Segundo Reis (2008), a mudança da paisagem local vem ocorrendo em função da atividade madeireira, das carvoarias e das roças que se transformam em pastagens. Após 10 anos de ocupação, o Assentamento Palmares II perdeu mais de $30 \%$ de sua área de floresta devido às práticas agrícolas dos agricultores familiares. A maior parte da renda da comunidade provém da produção agropecuária comercializada duas vezes por semana, na feira de produtores da cidade de Parauapebas, o que estimula a intensificação dos cultivos agrícolas.

\subsection{Agricultura familiar}

O conceito de agricultura familiar e a discussão sobre as políticas públicas para esse segmento só entrou em debate recentemente, a partir dos anos 90 (SCHMITZ e MOTA, 2007; DENARDI, 2001).
Segundo Schmitz e Mota (2007), toda a população agrária que administra um estabelecimento agrícola, como os assentados, agricultores de subsistência, posseiros, etc., deve ser incorporada na agricultura familiar. O estabelecimento familiar é simultaneamente uma unidade de produção e de consumo; uma unidade de produção e de reprodução social. Esses empreendimentos familiares têm duas características principais: gestão familiar e trabalho predominantemente familiar (DENARDI, 2001). Galvão et al. (2005) afirmam que, na unidade familiar, a produção se apoia no equilíbrio entre o consumo e o trabalho. Isso corresponde a uma microeconomia particular em que o volume de atividade é função direta do número de consumidores familiares e não do número de trabalhadores.

A agricultura familiar, além da diversificação da produção, ao contrário da agricultura convencional, busca equilibrar o uso dos recursos naturais atuando ativamente no processo de transição para uma agricultura sustentável (TOMASETTO et al., 2009). Para Veiga (1996), além da diversificação da produção, a vantagem da agricultura familiar é ter um perfil essencialmente distributivo e sustentável, além do fortalecimento dos agricultores.

Um projeto de desenvolvimento local sustentável para a agricultura familiar deve observar as especificidades regionais e adaptar culturas com maior potencial de produção, visto que a maior parte da produção agrícola mundial tem origem nos estabelecimentos familiares. Isso mostra a importância da formação de identidades e da diferenciação das regiões ao pensar em desenvolvimento local, enfatizando as preocupações com os aspectos sociais (ABRAMOVAY, 2000 apud TOMASETTO et al., 2009). Nesse sentido, a organização e a participação dos agricultores familiares no processo de desenvolvimento local devem buscar distribuição de renda e equidade social e, ao mesmo tempo, promovendo uma relação mais equilibrada com a natureza (TOMASETTO et al., 2009).

\subsection{A teoria do desenvolvimento local}

As diversas concepções sobre o desenvolvimento local estão relacionadas com a formação dos autores e seus pressupostos interpretativos. Oliveira (2001), por exemplo, entende o 
desenvolvimento local a partir de uma perspectiva histórica, condicionando o desenvolvimento local ao exercício da cidadania. $\mathrm{Na}$ concepção de Milani (2005), o desenvolvimento seria um conjunto que envolve atividades culturais, econômicas, políticas e sociais vistas sob uma ótica que o autor chama de intersetorial e trans-escalar, que participam de um projeto de transformação consciente da realidade local. Por sua vez, Companhola e Silva (2000) o definem como sendo um processo de construção coletiva, prevalecendo as necessidades sociais e culturais, devendo estar sincronizadas com as oportunidades locais de desenvolvimento, seja nos aspectos econômicos da inserção no mercado, seja em aspectos dos recursos naturais disponíveis e de sua conservação.

As experiências de desenvolvimento local se deram de forma diferente nas diversas partes do mundo: América Latina, América do Norte, Reino Unido etc. Cada um com sua trajetória histórica. $\mathrm{Na}$ teoria o desenvolvimento local, é o desenvolvimento de um determinado território que estava à margem do processo e encontrou um mecanismo de mudanças e transformações positivas, proporcionando qualidade de vida para os cidadãos (trabalho, renda, saúde, educação). Daí se têm experiências diferenciadas em todo o mundo. Ou seja, não há uma origem única para o desenvolvimento local, nem um caminho único, os caminhos devem ser construídos ${ }^{5}$.

A abordagem do desenvolvimento local sustentável enfatiza a dimensão territorial do desenvolvimento considerando as pessoas e as instituições - envolvidas em certos segmentos de reprodução social - como atores sociais. Propõe que o desenvolvimento atue no espaço rural, delimitado por um território. Considera que as comunidades devem explorar características e potencialidades próprias, na busca de especialização de atividades que lhes tragam vantagens comparativas de natureza econômica, social, política e tecnológica, aumentando a renda e as formas de riqueza, respeitando a preservação dos recursos naturais renováveis (CRUZ e VALENTE, 2004).

A perspectiva da abordagem territorial oferece outra visão de desenvolvimento, instigando os atores diversos a pensar seu futuro.

\footnotetext{
${ }^{5}$ Notas de aula do Programa de Pós-graduação em Gestão dos Recursos Naturais e Desenvolvimento Local - PPGEDAM 2009.
}

Pensar o desenvolvimento a partir da ideia de território surge como uma necessidade de potencializar mais as ações coletivas, fortalecer os grupos e organizações locais, os atores sociais, viabilizando uma maior interação entre estes. Logo, esse desenvolvimento precisa estar sintonizado com as demais dimensões: social, econômica, política, ecológica e cultural. No caso do território do sudeste do Pará, devido a sua complexidade, é importante repensar urgentemente, a partir do papel da agricultura familiar, uma nova lógica de desenvolvimento territorial (PTDRS, DO PARÁ, 2006).

\subsection{A produção agropecuária e o desenvol- vimento local}

Apesar de ser responsável por mais de $70 \%$ da produção de alimentos do país, ser a base econômica de cerca de $90 \%$ dos municípios, conservando a paisagem rural ocupada e produtiva (mesmo que em menor grau), a agricultura familiar brasileira depara-se com dificuldade em responder aos desafios de maior competitividade da agricultura interna e globalizada. Internamente, os desafios são de aumentar a produção de alimentos e, ao mesmo tempo, gerar novas oportunidades de trabalho e renda para os agricultores; promover a reconversão do êxodo rural e dos agricultores em processo de exclusão do meio produtivo (PROJETO PNUD/BRA/98/012, 1999).

Produzir na pequena propriedade rural tem sido possível, mesmo em condições adversas. Entretanto um dos grandes entraves para o produtor de pequena escala é a comercialização do excedente de sua produção. Uma das soluções encontradas para minimizar o problema tem sido a verticalização dessa produção. A verticalização agrega valor ao produto quando o transforma, e tira-o da condição de perecível quando permite ao produtor aguardar a hora adequada para comercialização, sem a necessidade de venda imediata após a colheita. Essa proposta de trabalho tem transformado o espaço rural brasileiro ocupado pelos pequenos produtores, em uma nova possibilidade de aumento de sua renda (LACERDA et al., 2007) e tornou-se uma alternativa interessante no contexto do desenvolvimento local das comunidades rurais. Em geral, a prática da agricultura pouco tem contribuído para o desenvolvimento local na Amazônia, devido a entraves como esses mencionados 
acima. Adicionalmente podemos citar a falta de financiamento, assistência técnica e infraestrutura nas comunidades rurais.

No território do sudeste do Pará, os lotes apresentam um uso diversificado, compostos de vários subsistemas: floresta, capoeira, pastagem para gado de cria e leite, culturas anuais e culturas perenes, horta e ervas medicinais, com destaque para a pecuária de leite em propriedades familiares no sudeste do Pará, que contribui decisivamente na estruturação de uma bacia leiteira no território (PTDRSPARÁ, 2006).

A dinâmica de comercialização de pro- dutos proveniente da agricultura familiar no sudeste do Pará se apresenta de forma bastante complexa, em que se destacam vários atores, com papéis diferenciados, formando uma cadeia de relações: Agricultura Familiar (produção agropecuária); Atravessador (compra produtos dos agricultores repassando a revendedores com preços mais altos); Cooperativas de Pequenos Produtores (adquirem os produtos direto das famílias com um preço melhor); Revendedor (comerciante ou feirante) e o Consumidor. A ilustração da comercialização é apresentada na figura 1.

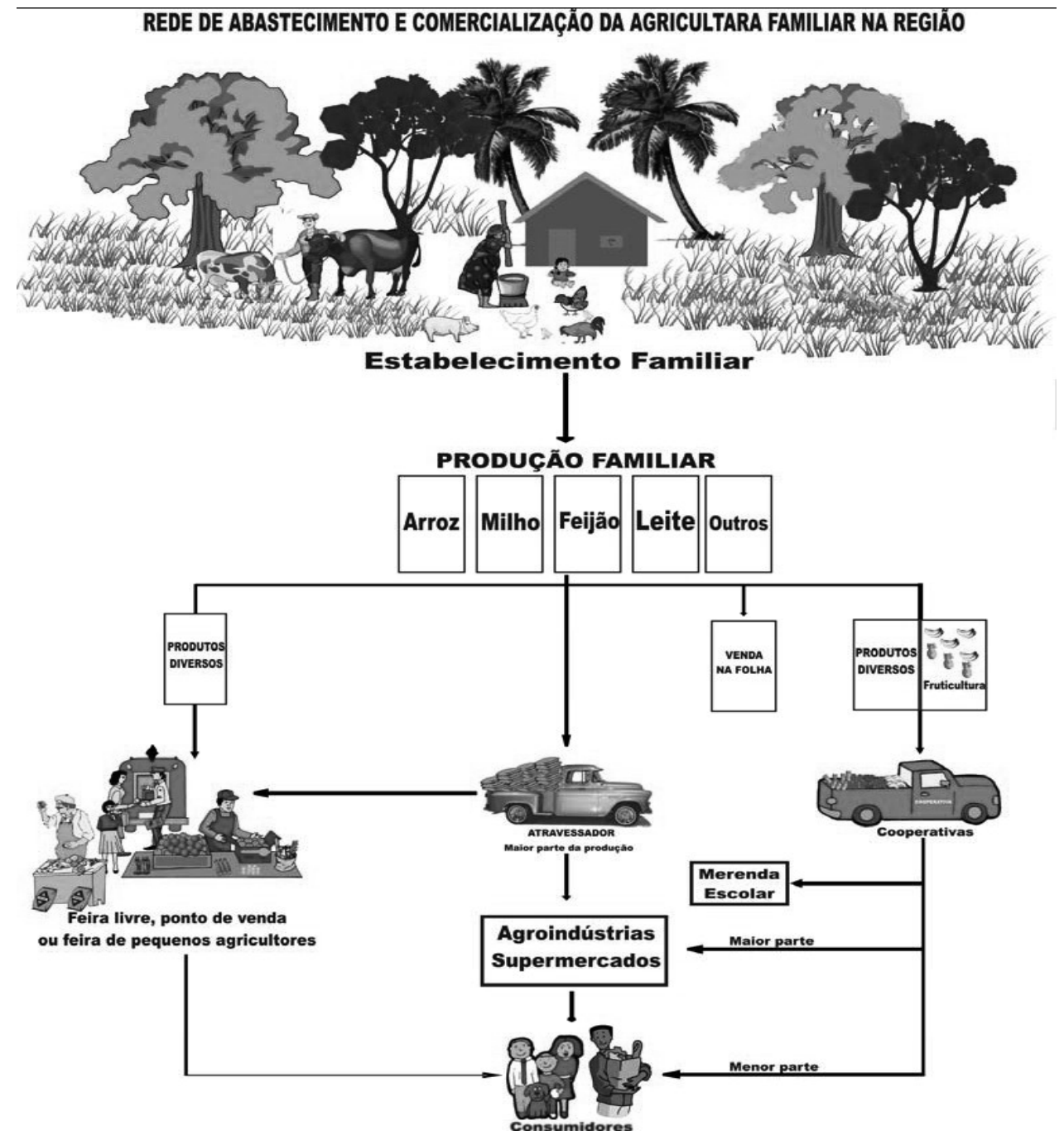

Figura 1 - Ilustração da dinâmica de comercialização no Território do Sudeste do Pará

Fonte: PTDRS (2006)

\footnotetext{
${ }^{6}$ A ilustração foi produzida a partir de um conjunto de entrevistas com feirantes e observações in loco nas feiras livres. Foram utilizadas ainda informações contidas nos Planos de Desenvolvimento dos municípios, Planos Plurianuais, PDA's dos assentamentos e outros (PTDRS, 2006)
} 
Em geral, o agricultor familiar, ao garantir o alimento para sua própria subsistência, dispõe para a venda o excedente de sua produção, mas, como não possui uma estrutura de armazenamento capaz de conservar seus produtos, precisa vender na primeira oportunidade para não perder a produção. Esses produtos comercializados têm grande importância no abastecimento do mercado local, em particular nas feiras livres existentes no território, oferecendo uma grande variedade de produtos aos consumidores urbanos (PTDRS, 2006).

\section{A situação econômico-ecológica da comu- nidade de Palmares II, Parauapebas, PA}

\subsection{A produção agropecuária no PA} Palmares II

No Projeto de Assentamento Palmares II, sudeste do Pará, a relação com o mercado local (no município de Parauapebas) é bastante estreita. Os agricultores familiares trabalham na produção de lavoura branca (mandioca, feijão, milho, arroz), produção de gado leiteiro, além da produção de hortaliças e de culturas permanentes, com destaque para a banana e para o abacaxi (MST, 2004; GTA, 2004).

Em um recente trabalho realizado no assentamento Palmares II, Souza et al. (2010) constataram a importância econômica dos cultivos anuais para os agricultores; cultivos de arroz, milho e mandioca, dos quais esta última apareceu como a principal cultura. Uma pesquisa realizada por Almeida (2010), na mesma localidade, também constatou a grande participação dos produtos do grupo mandioca e derivados na renda dos agricultores $(48,3 \%$ de importância econômica relativa). A predominância dos cultivos anuais, em Palmares II, é explicada pelo incentivo da Prefeitura municipal de Parauapebas com a disponibilização de mecanização agrícola aos agricultores (SOUZA et al., 2010; MICHELOTTI et al., 2010) e comercialização direta dos produtos na feira do produtor rural no município (SOUZA et al., 2010; ALMEIDA, 2010).

Um fator que contribui de maneira decisiva para o grande volume da produção familiar comercializada na comunidade de Palmares é a facilidade de acesso ao mercado.
A agrovila do Assentamento Palmares II encontra-se somente a $20 \mathrm{~km}$ da cidade de Parauapebas (a distância entre a agrovila e os lotes de produção oscila entre três a vinte quilômetros), com estrada totalmente asfaltada. Isso possibilita a participação de vários agricultores do Assentamento Palmares II na feira de Parauapebas, comercializando produtos agrícolas e olerícolas duas vezes por semana: quarta-feira e sábado (MICHELOTTI, 2008). Os agricultores se beneficiam também do transporte gratuito dos produtos agrícolas pelos caminhões da prefeitura, eliminando assim um agente considerado o "gargalo" da comercialização da agricultura familiar no território do sudeste do Pará: os intermediários/atravessadores que adquirem os produtos por um preço baixo, remunerando mal o produtor familiar.

A comunidade de Palmares II apresenta grandes potencialidades em termos de infraestrutura, educação e produção agrícola ligadas a uma sólida organização coletiva. No entanto ainda são necessárias melhorias em assistência técnica, maior apoio no transporte e financiamento para promover a diversificação da produção e aumento da renda para as famílias. São Instrumentalizações necessárias com vistas ao desenvolvimento local dessa comunidade.

\subsection{A sustentabilidade econômico-ecológica do PA Palmares II}

O conceito de sustentabilidade supõe a garantia da permanência dos fatores fundamentais de desenvolvimento, em um ambiente e/ou sociedade, impedindo ou postergando seu perecimento. A sustentabilidade disso está nas mãos da própria localidade, na medida em que esta assume a responsabilidade social desse processo. É necessário, portanto, o desenvolvimento de estratégias que garantam o envolvimento dos atores sociais locais e seu comprometimento com a sustentabilidade socioeconômica e ambiental da localidade (PROJETO PNUD/BRA/98/012, 1999).

Para Alves e Homma (2004), as precárias condições socioeconômicas e ambientais da maioria dos assentamentos da reforma agrária no sul e sudeste paraense são consequências, além de outros fatores, do modelo de uso da terra, respaldado na pecuária com 
baixos índices de produtividade e como atividade principal. No médio prazo, ocorrerá a completa degradação das pastagens e o esgotamento dos recursos florestais. Nesse contexto, a alternativa de curto prazo é a diversificação da propriedade com a integração agricultura/pecuária. Na realidade, assegurar condições para o desenvolvimento da produção e da renda sem comprometer o meio ambiente constitui o principal desafio (ALVES e HOMMA, 2004).

Na comunidade de Palmares II, pode-se observar uma diminuição de mais da metade da área florestal após 10 anos de ocupação (Tabela 1). As áreas de florestas desmatadas entre 1994 e 2005 foram principalmente transformadas em pastagens e roças. Durante esse período, a proporção de capoeiras aumentou de maneira significativa.

Tabela 1 - Evolução da cobertura vegetal em Palmares II

\begin{tabular}{lcc}
\hline \multicolumn{1}{c}{ Cobertura Vegetal } & $\mathbf{1 9 9 4}$ & $\mathbf{2 0 0 5}$ \\
\hline Mata & $59,23 \%$ & $26,79 \%$ \\
Pastagem & $36,98 \%$ & $44,84 \%$ \\
Capoeira & $3,03 \%$ & $18,37 \%$ \\
Roças & - & $6,97 \%$ \\
Perenes e Semiperenes & - & $1,70 \%$ \\
\hline
\end{tabular}

Fonte: Adaptado de Levantamento de campo Reis (2008).

A facilidade de transporte em função da localização e, consequentemente, as melhores possibilidades de comercialização, além do maior acesso ao crédito e do menor tamanho dos estabelecimentos - 25 hectares (a média na região é de 60 ha) levaram a uma intensificação do uso do solo em Palmares (MICHELOTTI, 2008). Os agricultores familiares têm procurado aumentar sua produção para suprir a demanda da cidade, com aquisição de financiamentos para compra de equipamentos agrícolas que garantam maior agilidade no preparo das áreas de plantio, equipamentos de beneficiamento, entre outros, visando a um maior aproveitamento da área existente. Isso influenciou o aumento da renda familiar. Todavia esses aumentos da produção agrícola estão geralmente ligados a um avanço preocupante do desmatamento nos estabelecimentos familiares, a utilização intensiva do solo leva ao rápido esgotamento dos nutrientes, diminuindo a produção. Como a reprodução econômico-social das famílias é baseada na agricultura de corte-queima, continuando nesse ritmo de desmatamento, o sistema entrará em crise, com o esgotamento dos recursos florestais. Além das consequências ecológicas, Michelotti (2008) alerta em relação ao aspecto econômico-social, pois há uma grande dependência da atividade agrícola para a reprodução econômica das famílias.

A biodiversidade constitui-se a base da estabilidade ecológica, pois trata-se de um atributo da natureza que é indispensável para o bom funcionamento dos ecossistemas que integram o meio ambiente (SHIVA, 2003). Entre alguns bens e serviços desse importante componente dos sistemas ecológicos, que é a biodiversidade, podemos citar: regulação do clima; ciclagem de nutrientes; formação do solo; controle da erosão; produção de alimentos e matérias-primas, dentre outros (FEARNSIDE, 2003). As grandes possibilidades de uso da biodiversidade (pelo que já se conhece e pelo seu potencial) oferecem justificativas para esforços no sentido de evitar sua perda (ARAÚJO, 2007).

Dados do projeto de pesquisa AMAZ_ ES - grupo biodiversidade, obtidos através de levantamento de campo em 9 estabelecimentos familiares no Assentamento Palmares II, demonstraram que foram encontradas 707 espécies de plantas em 45 parcelas amostradas. As parcelas representativas dos diferentes usos da terra, que apresentaram as maiores riquezas de espécies foram: floresta explorada $(77,8 \pm 18,6)$; floresta queimada $(65,1 \pm 23,5)$, seguido das áreas onde predominam as pastagens invadidas $(44 \pm 12,3)$ e as capoeiras (capoeira velha $[45 \pm 5,6]$ e capoeira jovem $[42,8$ $\pm 10,7]$ ); e, por ordem decrescente de riqueza, estão as roças (roças de milho [33,6 6 9]; roças de mandioca [31,5]; roças de arroz [24 \pm 2$]$ ); e por fim a terra gradeada (21) e as pastagens limpas $(20,1 \pm 8,9)$. Sendo assim, as roças (de milho, mandioca e arroz), a terra gradeada e as pastagens limpas foram consideradas como áreas que geram mais impacto na biodiversidade. Por outro lado, como foi constatado anteriormente, as roças são as atividades de maior importância econômica para os agricultores do Assentamento Palmares II.

Para se atingir a sustentabilidade econômico-ecológica no Assentamento Palmares II, devem ser concebidas e testadas práticas alternativas em direção a uma atividade agro- 
pecuária integrada à paisagem florestal do assentamento (MICHELOTTI e RODRIGUES, 2004). Nesse sentido, são importantes os estímulos às atividades agroflorestais, agrossilvipastoris e extrativistas. Em um estudo realizado no Projeto de Assentamento Benfica (município de Itupiranga, região sudeste do Pará), foram inventariadas árvores e palmeiras nativas que conseguem se manter nas pastagens durante muitos anos, desde que sejam preservadas no desmatamento inicial pelo agricultor. Nessa lista, encontram-se árvores de uso múltiplo que poderiam ser preconizadas para arborização de pastagens sem trabalho adicional nem investimento (SANTOS, 2007; SANTOS e MITJA, no prelo). Dezenove das 21 espécies preconizadas nos 2 trabalhos citados estão presentes em Palmares II, são elas: castanheira (Bertholletia excelsa), babaçu (Attalea speciosa), bacaba (Oenocarpus distichus), tucumã (Astrocaryum tucuma), jacarandá (Swartzia flaemingii), pente de macaco (Apeiba tibourbou), pau preto (Cenostigma tocantinum), taperebá (Spondias mombin), quina (Geissospermum vellosii), matá-matá (Eschweilera coriacea), goiabão (Chrysophyllum lucentifolium), jarana (Lecythis lurida), pará-pará (Jacaranda copaia), sumaúma (Ceiba pentandra), canafista (Cassia fastuosa), ingá (Inga edulis), inajá (Attalea maripa), melancieiro (Alexa grandiflora), tatajuba (Bagassa guianensis) (SANTOS, 2011). Além de serem importantes para o maior conforto do rebanho, de auxiliar na alimentação da família e nas construções na propriedade, essas espécies florestais são capazes de ficar por muitos anos nos ambientes cultivados e podem ser utilizadas para aumentar a biodiversidade nos sistemas cultivados dos agricultores familiares da comunidade de Palmares II.

Um estudo realizado por Ward (2006) mostra que, na comunidade de Palmares II, já existe certa preocupação ambiental, identificada, por exemplo, pela consciência dos problemas ambientais na localidade, pelo senso de responsabilidade na gerência dos problemas identificados e pelo início de ações para conservação. A predisposição da comunidade para a conservação dos recursos naturais é necessária na concretização de um eventual projeto de cunho ambiental.

\section{Conclusões}

A dificuldade de comercialização encontrada pelos pequenos produtores no sudeste do Pará constitui-se um dos maiores desestímulos à produção agrícola regional. No entanto, na comunidade de Palmares, cuja vila de moradores fica a $20 \mathrm{~km}$ da cidade, o fácil acesso (estradas vicinais) e a infraestrutura (estrada asfaltada) possibilitam aos agricultores comercializarem seus produtos na Feira do Produtor Rural da cidade de Parauapebas, resultando em ótimas oportunidades de negócio e consequente aumento da renda familiar. $\mathrm{O}$ Assentamento apresenta, portanto, potencialidades para o desenvolvimento local.

Apesar da perspectiva para o aumento da produção de alimentos visando atender a demanda local com um maior aproveitamento da área existente, há o problema do tamanho dos lotes do assentamento. A área restrita para a produção agrícola favorece a utilização intensiva do solo, que já é pobre em nutrientes e chega ao rápido esgotamento, proporcionando uma diminuição da produção. A prática da agricultura de corte-queima pelos agricultores gera o desflorestamento acelerado dos lotes e compromete a reprodução socioeconômica da família. A floresta representa uma reserva de nutrientes importante para o cultivo das roças e, futuramente, o esgotamento do recurso florestal poderá gerar uma crise no sistema produtivo local.

No Projeto de Assentamento Palmares II, torna-se de primordial importância: incentivar e apoiar práticas de produção que levem a um aumento da biodiversidade nos estabelecimentos através da instalação de sistemas agroflorestais incluindo espécies alóctones (exóticas) ou conservando espécies autóctones (nativas); promover atividades de capacitação com articulação da associação do assentamento junto aos governos, no sentido de preconizar técnicas agrícolas que preservem os recursos naturais; promover capacitação para a agroindustrialização do excedente (agregando valor ao produtor) e contribuir para inserção desses produtos industrializados no mercado local. O fato de a comunidade demonstrar preocupação com a preservação do assentamento é um passo importante e bastante necessário quando da implementação de qualquer medida conservacionista. 


\section{Referências}

ABRAMOVAY, R. O capital social dos territórios: repensando o desenvolvimento rural. Revista de Economia Aplicada, São Paulo, n. 2, v. IV, p. 379-397, abril/junho 2000. Disponível em: <http://abramovay.pro.br/>. Acesso em: 30 mar. 2010.

ALMEIDA, A. P. O. Feira do produtor rural de Parauapebas, $P A$ : aspectos econômicos e sociais. 2010.57f. Monografia (Curso de Agronomia) - Universidade Federal do Pará, Marabá, PA, 2010.

ALVES, R. N. B.; HOMMA, A. K. O. Pecuária versus diversificação da produção nos Projetos de Assentamentos no Sudeste Paraense. Comunicado Técnico, 97, Belém, Embrapa Amazônia Oriental, p. 1-6, agosto 2004.

ARAÚJO, M. A. R. Unidades de Conservação no Brasil: da república à gestão de classe mundial. Belo Horizonte: SEGRAC, 2007. 272 p.

COMPANHOLA, C.; SILVA, J. G. Desenvolvimento local e a democratização dos espaços rurais. Cadernos de Ciência E Tecnolologia, Brasília, v. 17, n. 1, p. 11-40, jan./abr. 2000.

CRUZ, K. C. M. S.; VALENTE, A. L. E. F. Produção familiar, agronegócio e desenvolvimento local sustentável em área remanescente de quilombo um estudo de caso na comunidade Kalunga. In: CONGRESSO DA SOCIEDADE BRASILEIRA DE ECONOMIA ESOCIOLOGIA RURAL, 42. 2004, Cuiabá. Anais...Cuiabá, MT, p. 487-487, 2004.

DENARDI, R. A. Agricultura familiar e políticas públicas: alguns dilemas e desafios para o desenvolvimento rural sustentável. Agroecol.e Desenv. Rur. Sustent., Porto Alegre, v. 2, n. 3, jul./set. 2001.

FEARNSIDE, P. M. A floresta amazônica nas mudanças globais. Manaus: INPA, 134 p., 2003.

GALVÃO, E. et al. Análise da renda e da mão-de-obra nas unidades Agrícolas Familiares da Comunidade de Nova Colônia, Município de Capitão Poço, Pará. Amazônia: Ciência \& Desenvolvimento, Belém, v. 1, n. 1, jul. /dez. 2005.

GRUPO DE TRABALHO AMAZÔNICO. Assentados de Palmares comemoram dez anos. 2004. Disponível em: <http://www.gta.org.br/noticiasexibir. php? codcel=385>. Acesso em: 02 nov. 2009.

GUILHOTO, J. et al. A importância do agronegócio familiar no Brasil. RER, Rio de Janeiro, v. 44, n. 03, p. 355-382, jul/ set 2006.

LACERDA, L. et al. Agroindustrialização de alimentos nos assentamentos rurais do entorno do Parque Nacional da Serra da Bodoquena e sua inserção no mercado turístico, Bonito/MS. INTERAÇÕES, v. 8, n. 1, p. 55-64, mar. 2007.

MINISTÉRIO DO DESENVOLVIMENTO AGRÁRIO (MDA). Políticas integradas para reduzir desigualdades. Jornal Territórios da Cidadania: Brasília, março de 2008.

MINISTÉRIO DO DESENVOLVIMENTO AGRÁRIO (MDA) / SECRETARIA DE DESENVOLVIMENTO TERRITORIAL (SDT). Estudo propositivo para dinamização econômica território rural do sudeste paraense. Brasília, 2007. Disponível em: <http:/ / serv-sdt-1.mda. gov.br/biblioteca_virtual/ep/EP_PR_Vale_do_Ribeira. pdf>. Acesso em: 13 Maio 2010.
MELO, D. R. G. A. Dados recentes do agronegócio brasileiro. Revista da UFG, v. 7, n. 01, junho 2004. (on line). Disponível em: <http://www.proec.ufg.br>. Acesso em: 25 out. 2009.

MICHELOTTI, F. Luta pela terra e assentamentos no sudeste do Pará. In: ENCONTRO DA REDE DE ESTUDOS RURAIS, 3. Campina Grande, PB, 2008. Disponível em: <www.redesrurais.org.br/sites/...3encontro/.../ Beatriz\%20Ribeiro.pdf $>$.

MICHELOTTI, F.; RODRIGUES, F. N. C. V. Desafios para a sustentabilidade ecológica integrada a trajetórias de estabilização da agricultura familiar na região de Marabá. Novos Cadernos NAEA, v. 5, p. 73-103, 2004.

MICHELOTTI, F.; SOUZA, H.; ALMEIDA, A. P. O. Estratégias de comercialização e reprodução camponesa no sudeste Paraense: a participação do Assentamento Palmares II na Feira do Produtor Rural de Parauapebas/ PA. In: ENCONTRO DA REDE DE ESTUDOS RURAIS, 4. Anais... Curitiba, julho de 2010.

MILANI, C. Teorias do capital social e desenvolvimento local: lições a partir da experiência de Pintadas (Bahia). Salvador: UFBA; NPGA/NEPOL/PDGS, 2005.

MINISTÉRIO DA AGRICULTURA. Agronegócio brasileiro: uma oportunidade de investimentos. Disponível em: <http://www.agricultura.gov.br/portal/page? pageid $=33,968707 \&$ dad $=$ portal $\&$ schema $=$ PORTAL $>$. Acesso em: 01 nov. 2009.

MOVIMENTO DOS TRABALHADORES RURAIS SEM TERRA. Projeto de assentamento do Pará comemora dez anos. Junho de 2004. Disponível em: <http:/ / www.mst.org. br/node/2044>. Acessado em: 02 nov. 2009.

OLIVEIRA, E. R.; RIBEIRO, E. M. Indústria rural, agricultura familiar e desenvolvimento local: o caso da produção de cachaça artesanal em Salinas-Minas Gerais. In: SEMINÁRIO SOBRE A ECONOMIA MINEIRA, 10. 2002, Anais... Diamantina, MG, 2002.

OLIVEIRA, F. Aproximações ao enigma: que quer dizer desenvolvimento local? In: OLIVEIRA, F. et al. Novos contornos da gestão local: conceitos em construção. São Paulo: Pólis, 2001. p. 11-31.

PINTO, J. N. A.; SILVA, L. Elementos para a compreensão da dinâmica do agronegócio na Amazônia. Texto do Projeto de Desenvolvimento do "Pará Rural", julho 2005.

PROJETO PNUD/BRA/98/012. Agricultura Familiar no Contexto Desenvolvimento Local Sustentável. PRONAF/ SDR/PNUD, 1999.

Plano Territorial de Desenvolvimento Rural Sustentável do Sudeste do Pará (PTDRS). Laboratório Sócio Agronômico do Tocantins (LASAT). Marabá, PA: UFPA, 2006.

REIS, D. A. Diagnóstico da qualidade do solo, segundo o saber acadêmico e a percepção do agricultor, nos sistemas de Roça e Pasto no Assentamento Palmares II. 2008. 75 f. Monografia (Trabalho de Conclusão de Curso em Agronomia) - Universidade Federal do Pará, Marabá, PA, 2008.

SANTOS, A. M. Estrato arbóreo nas pastagens de agricultores familiares da comunidade de Benfica, Itupiranga-PA. 2007. 79 f. Monografia (Trabalho de Conclusão de Curso em Agronomia) - Universidade Federal do Pará, Marabá, PA, 2007. 
SANTOS, A. M. Consequências das práticas agrícolas na diversidade vegetal em Parauapebas, Pará. 2011. 93 f. Dissertação (Mestrado em Gestão dos Recursos Naturais e Desenvolvimento Local na Amazônia) - Universidade Federal do Pará/NUMA, Belém, PA, 2011.

SANTOS, A. M; MITJA, D. Pastagens arborizadas no Projeto de Assentamento Benfica, município de Itupiranga, Pará, Brasil. Rev. Árvore, Viçosa, MG. (no prelo) SCHMITZ, H.; MOTA, D. M. Agricultura Familiar: elementos teóricos e empíricos. Revista Agrotrópica. Itabuna, v. 19, p. 21-30, 2007.

SHIVA, V. Monoculturas da mente: perspectivas da biodiversidade e da biotecnologia. São Paulo: Gaia, 2003.

SOUZA, H. et al. A reprodução sócio-econômica e produtiva do campesinato no Sudeste Paraense: o Assentamento Palmares II, Parauapebas/PA. In: CONGRESSO
DO CAMPUS DE MARABÁ: PRÁTICAS, SABERES E REFLEXÕES NA CONSTRUÇÃO DE UMA UNIVERSIDADE, 1. Marabá, 21 out. 2010.

TOMASETTO, M. Z. C.; LIMA, J. F.; SHIKIDA, P. F. A. Desenvolvimento local e agricultura familiar: o caso da produção de açúcar mascavo em Capanema - Paraná. INTERAÇÕES, Campo Grande, v. 10, n. 1, p. 21-30, jan./jun. 2009.

VEIGA, J. E. Agricultura familiar e sustentabilidade. Cadernos de Ciência e Tecnologia. Brasília, DF, v. 13, n. 3, p. 383-404, set./dez. 1996.

WARD, C. C. Piecing Together Social and Environmental Priorities in the Ongoing Process of Community Development In the MST Assentamento of Palmares II. Duke University - Nicholas School of the Environment, 2006. Disponível em: <http://digitalcollections.sit.edu/ ispcollection/280>. Acesso em: 04 nov. 2009. 